\title{
Zingerone alleviates cadmium-induced nephrotoxicity in rats via its antioxidant and anti-apoptotic properties
}

\author{
Shauq Mumtaz Dawood* (D), Farah Mumtaz² (D), Raju Padiya (D) \\ 'Department of Biochemistry, College of Science, Osmania University, Hyderabad-500007, Telangana State, India \\ 2Department of Zoology and Entomology, Faculty of Science, Helwan University, Cairo, Egypt \\ *Corresponding author: sh_19792000@yahoo.com
}

\begin{abstract}
Objectives: Cadmium is an essential industrial metal and acts as an environmental toxicant that is a major cause of kidney diseases. Hence, we aimed to evaluate the possible nephroprotective effects of zingerone (ZGO), a major flavonoid constituent in ginger (Zingiber officinale) dry roots, against cadmium-induced nephrotoxicity in rats. Methods: In this study, Wistar albino rats [ACUC: HU2020/Z/FMS0120-01] were allocated randomly to 4 groups with seven animals in each group. The control group which received physiological saline; cadmium chloride $\left(\mathrm{CdCl}_{2}\right)$ treatment group which received $\mathrm{CdCl}_{2}$ at a dose of $6.5 \mathrm{mg} / \mathrm{kg}$ intraperitoneally (i.p.) for 7 consecutive days; zingerone treatment group which received $25 \mathrm{mg} / \mathrm{kg}$ of zingerone orally for 7 consecutive days and $\mathrm{CdCl}_{2}$ (6.5 mg/kg; i.p.)+ZGO (25 mg/kg; p.o.) treatment group which received $\mathrm{CdCl}_{2}$ and $\mathrm{ZGO}$ for 7 consecutive days. Results: Co-administration of $\mathrm{ZGO}$ along with $\mathrm{CdCl}_{2}$ resulted in a significant reduction in creatinine and urea levels of serum. Additionally, ZGO significantly diminished the tissue levels of $\mathrm{Cd}$ concentration, lipid peroxidation, and nitric oxide and significantly recovered the enzymatic and nonenzymatic antioxidant molecules, namely glutathione, total superoxide dismutase, catalase, and glutathione recycling enzymes peroxidase and reductase, in kidney tissue. Furthermore, ZGO treatment prevented the inflammation produced by $\mathrm{CdCl}_{2}$ by restraining the elevation in the level of pro-inflammatory cytokines (tumor necrosis factor-alpha and interleukin1 beta). Moreover, ZGO improved histopathological alternations in the kidney by preventing apoptosis cascade in kidney tissue by stimulating Bcl-2 and suppressing Bax and caspase-3. Conclusions: Our findings suggest that ZGO has nephroprotective activity in cadmium-induced nephrotoxicity mostly via modulating of oxidant/antioxidant balance, inflammatory response, and apoptosis.
\end{abstract}

Keywords: Zingerone. Cadmium. Nephrotoxicity. Oxidant/Antioxidant Imbalance. Inflammation. Cell Death.

\section{How to cite}

Dawood SM, Farah M, Padiya R. Zingerone alleviates cadmium-induced nephrotoxicity in rats via its antioxidant and anti-apoptotic properties. Rev Ciênc Farm Básica Apl. 2022;43:e759.

https://doi.org/10.4322/2179-443X.0759

\section{INTRODUCTION}

Heavy metals toxicity represents a major health problem worldwide. Furthermore, the grown manufacturing pollutions due to fast growth in the human populations have exponentially worsened environmental problems ${ }^{1}$. Heavy metals are poisonous chemicals 
discharged into the soil, water, and atmosphere, which then reuptake into the food chains. Cadmium (Cd) is a toxic metal, which has unidentified health profits and is characterized by an elongated biological half-life (about thirty years in humans) with a small rate of elimination from the body ${ }^{2}$. Cd exposure has induced oxidative stress, which may cause DNA damage, protein modification, and lipid peroxidation, which may lead to conditions such as kidney dysfunction, anemia, tumor, and bone weakness ${ }^{3}$. The mechanisms of Cd-induced tissue damage are not entirely understood; however, assorted mechanisms, including oxidative pressure, inflammation, and stimulation of cell-death pathways, are thought to be implicated. Acute exposure to $\mathrm{Cd}$ resulted in the production of free radicals that enhance reactive oxygen species (ROS) generation and contribute to vigorous oxidative pressure. Inflammation and cell death are also key markers for Cd-induced cell injury ${ }^{4}$.

With the constant, low-level pattern of $\mathrm{Cd}$ exposure, the principal target organ of $\mathrm{Cd}$ toxicity is the kidney, in which $\mathrm{Cd}$ causes a comprehensive dysfunction in different renal cells and enhances the urinary excretion of amino acids, glucose, electrolytes (mainly $\mathrm{Na}^{+}, \mathrm{K}^{+}$, and $\mathrm{Ca}^{2+}$ ) and lowmolecular-weight proteins ${ }^{5}$. Furthermore, $\mathrm{Cd}$ exposure induces reduction in glomerular filtration rate (GFR) and reserve filtration capacity ${ }^{1}$. Hence, the primary strategy to mitigate Cd toxicity is to enhance $\mathrm{Cd}$ removal by chelator agents; however, adverse effects are obvious with this strategy. Fortunately, there is another approach that can be used to mitigate the Cd-induced oxidative stress, i.e., the utilize of natural products, particularly antioxidants ${ }^{6}$. Zingerone or 4-(4-Hydroxy-3 methoxyphenyl) butan-2-one) is a vanillylacetone flavonoid found mainly in ginger (Zingiber officinale) which is considered as the major active constituent in the dry roots ${ }^{7-9}$. Zingerone showed a wide range of remedial effects such as anti-inflammatory, anti-nausea, anti-emesis, anti-obesity, anticancer, antimicrobial, and antidiuretic activities ${ }^{10}$. Besides, zingerone has critical roles in the enhancement of antioxidants, scavenging free radicals, and conserving mitochondria against toxicity ${ }^{11}$. Therefore, the current experiment was aimed to examine the influence of zingerone on cadmium-induced nephrotoxicity in rats via attenuating oxidative stress, inflammation, and apoptosis in kidney tissue.

\section{MATERIAL AND METHODS}

\section{Chemical and materials}

Cadmium chloride $\left(\mathrm{CdCl}_{2}\right)$ and zingerone (ZGO) were obtained from Sigma-Aldrich, St. Louis, USA. In this experiment, the chosen doses which rats treated with $6.5 \mathrm{mg} / \mathrm{kg}$ body weight (b.wt.) $\mathrm{CdCl}_{2}$ and/or $25 \mathrm{mg} / \mathrm{kg}$ b.wt. ZGO was based on the published studies of Elkhadragy et al. ${ }^{12}$ and Kaygusuzoglu et al. ${ }^{7}$, respectively. In this regard, Elkhadragy et al. ${ }^{12}$ reported that $\mathrm{Cd}$ administration for seven days was able to induce nephrotoxicity evidenced by elevation in kidney function parameters and pathological alternations in kidney tissue. While ZGO is safe up to $100 \mathrm{mg} / \mathrm{kg}$ b.wt.

\section{Animals grouping}

Twenty-eight adult male Sprague-Dawley rats of 9-10 weeks old weighing 185-200 g were obtained from the EGY-VAC, Cairo, Egypt. The rats were kept in plastic cages under a standard laboratory environment $\left(22-25{ }^{\circ} \mathrm{C}, 50-60 \%\right.$ humidity) with ad libitum access to a balanced rodent diet and water. All investigational procedures were employed according to the European Community Directive (86/609/EEC) and the Animal Care and Use committee at Department of Zoology, Faculty of Science, Helwan University (approval no. HU2020/Z/FMS0120-01). Seven days after adaptation, the rats were randomly assigned into four equal groups of seven rats each as follows: Control group which daily received a physiological saline via the oral administration ( $3 \mathrm{ml} / \mathrm{kg}$ b.wt.; p.o.), $\mathrm{CdCl}_{2}$ group which received $\mathrm{CdCl}_{2}$ at a dose of $6.5 \mathrm{mg} / \mathrm{kg}$ intraperitoneally (i.p.) for 7 consecutive days, ZGO group which received $25 \mathrm{mg} / \mathrm{kg}$ of zingerone orally for 7 consecutive days and $\mathrm{CdCl}_{2}$ (6.5 mg/kg b.wt.; i.p.)+ZGO ( $25 \mathrm{mg} / \mathrm{kg}$ b.wt.; p.o.) group. All the rats were sacrificed via euthanasia under an overdose of pentobarbital (100 mg/kg i.p.) 
after 24 hours after last administration. The kidneys of the rats were removed immediately and stored in formalin for histological examinations or at $-80{ }^{\circ} \mathrm{C}$ for subsequent biochemical experiments. At the time of sacrificing, blood samples were collected and serum was obtained by centrifugation at $3000 \times \mathrm{g}$ for $10 \mathrm{~min}$.

\section{Estimation of $\mathrm{Cd}$ concentration in the renal tissue}

Cadmium concentration in the renal tissues was estimated using a standardized process as described earlier with some modifications ${ }^{12}$. Briefly, $200 \mathrm{mg}$ of renal samples was digested with $2000 \mu \mathrm{L}$ of conc. nitric acid (65\%-ACS grade; Sigma-Aldrich) in an oven at $90{ }^{\circ} \mathrm{C}$ for $10 \mathrm{~h}$. After digestion, Cd level was analyzed at $283.3 \mathrm{~nm}$ using a graphite furnace atomic absorption spectrophotometry. Cd concentrations in renal tissue were represented as $\mu \mathrm{g} / \mathrm{g}$ of wet renal tissue.

\section{Histopathological assessment}

Kidney samples were fixed in $10 \%$ neutralized-buffered formalin for a day at $27{ }^{\circ} \mathrm{C}$. After fixation, the samples were dehydrated, embedded in paraffin wax, and sectioned to 4-5 $\mu \mathrm{m}$ section. The deparaffinized slides were stained with hematoxylin and eosin for light microscopy. Images were snapped using Axioplan Imaging System (MC200, Carl Zeiss Inclusive, Germany).

\section{Ethics statement}

All investigational procedures were employed according to the European Community Directive (86/609/EEC) and the Animal Care and Use committee at Department of Zoology, Faculty of Science, Helwan University (approval no. HU2020/Z/FMS0120-01).

\section{Reporting guidelines:}

The study followed ARRIVE guidelines. Data will be provided by the authors upon justified request.

\section{Biochemical parameters}

\section{Kidney function assays}

Blood urea and creatinine levels were determined by using reagent assay kits (BioDiagnostic Co., Giza, Egypt).

\section{Estimation of renal oxidants and antioxidants parameters}

Each kidney sample was homogenized with 10 times the volume of ice-cold $50 \mathrm{mM}$ potassium phosphate buffer $(\mathrm{pH}$ 7.4) and the supernatant was separated by centrifugation at $3000 \times \mathrm{g}\left(4^{\circ} \mathrm{C}\right)$ for $10 \mathrm{~min}$. The supernatants were used for the estimation of thiobarbituric acid reactive substances (TBARS) as a marker of lipid peroxidation, nitric oxide (NO; nitrite/nitrate), reduced glutathione (GSH), catalase (CAT), total superoxide dismutase (T-SOD), and glutathione recycling enzymes [glutathione peroxidase (GSH-Px) and glutathione reductase (GSH-R)] according to the commercial kits manual (BioDiagnostic Co., Giza, Egypt).

\section{Determination of inflammatory and apoptotic markers}

Pro-inflammatory cytokines in the renal tissues were estimated by ELISA using commercial kits. Tumor necrosis factor-alpha (TNF-a) and interleukin-1 beta (IL-1 $\beta$ ) were assayed using a rat ELISA kit (CUSABIO Life Sciences, Wuhan, China). Whereas, Bcl-2, Bax, and caspase-3 levels in the renal tissues were measured using a rat ELISA kit (CUSABIO Life Sciences, Wuhan, China). The plates were analyzed at $450 \mathrm{~nm}$ using the ELISA microplate reader. The procedure was done according to the manufacturer's protocols. 


\section{Statistical analysis}

All values were represented as the means \pm standard deviation (SD). Data were analyzed by one-way ANOVA followed by Tukey's post hoc test using a statistical package program (SPSS version 20.0); significance was set at $p \leq 0.05$.

\section{RESULTS}

Cadmium chloride administered for 7 days declined extensively $(p<0.05)$ the body weight of the rats compared to the healthy rats (Figure 1). However, the body weights of the ZGOtreated rats intoxicated with $\mathrm{CdCl}_{2}$ were higher than those of the $\mathrm{CdCl}_{2}$-exposed rats and the body weights were returned back to the control values. The rats treated alone with ZGO showed a non-significant diminish in body weight compared to the healthy animals.

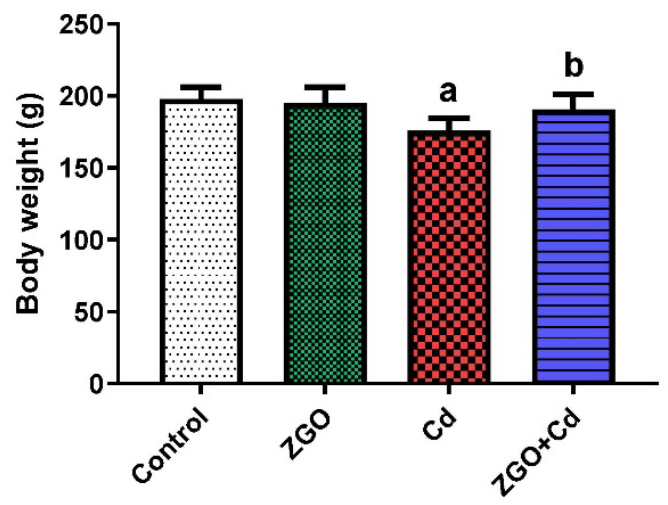

Fig. 1. Effects of zingerone $(\mathrm{ZGO})$ on bodyweight changes of $\mathrm{CdCl}_{2}$-intoxicated rats. Data are expressed as the mean $\pm \mathrm{SD}(n=7)$. ${ }^{a} p<0.05$ vs. the control rats; ${ }^{b} p<0.05$ vs. the Cd-intoxicated rats.

Experimental groups treated with $\mathrm{CdCl}_{2}$ had a statistically elevated $(p<0.05)$ renal concentration of $\mathrm{Cd}$ compared to values in the healthy animals. However, the $\mathrm{Cd}$ concentration in the ZGO-treated group was extensively decreased compared to that in the $\mathrm{CdCl}_{2}$-intoxicated animals (Figure 2).

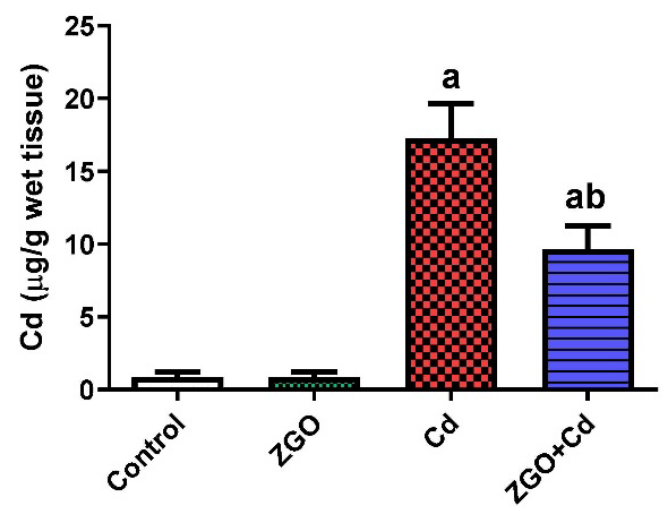

Fig. 2. Effects of zingerone ( $\mathrm{ZGO}$ ) on cadmium concentration in the renal tissue of $\mathrm{CdCl}_{2}$-intoxicated rats. Data are expressed as the mean $\pm \mathrm{SD}(\mathrm{n}=7)$. ${ }^{\mathrm{a}} p<0.05$ vs. the control rats; ${ }^{\mathrm{b}} p<0.05$ vs. the Cd-intoxicated rats.

As presented in Figure 3, the renal tissue of the healthy and ZGO-treated rats showed ordinary kidney architecture with regular morphology of glomeruli, proximal, and distal tubular 
cells (Figures 3A and 3B). However, the examination of the kidney tissue of the $\mathrm{CdCl}_{2}$-intoxicated rats exhibited congested glomeruli, severe infiltration of inflammatory cells, cytoplasmic vacuolation, and tubular atrophy or desquamation and degeneration (Figure 3C), while ZGO treatment limited the pathological alterations caused by $\mathrm{CdCl}_{2}$ intoxication (Figure 3D).

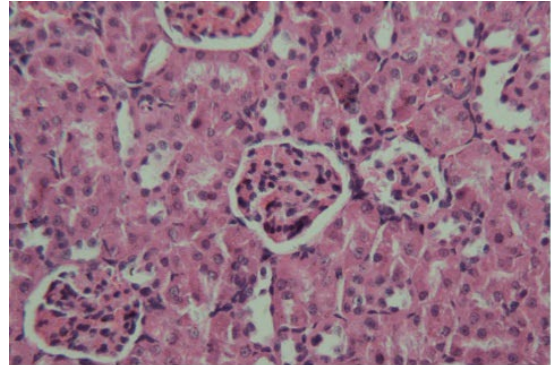

(a) Control

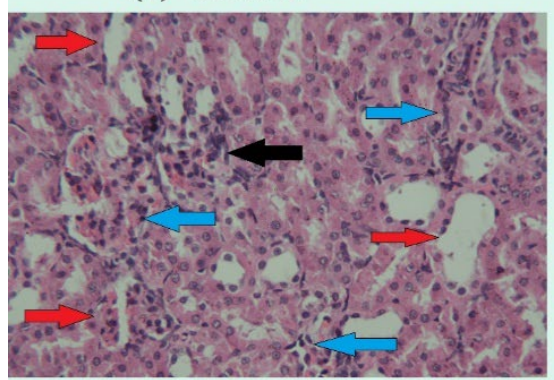

(c) $\mathrm{Cd}$

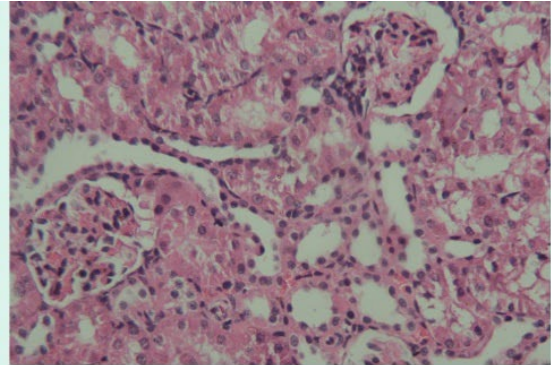

(b) ZGO

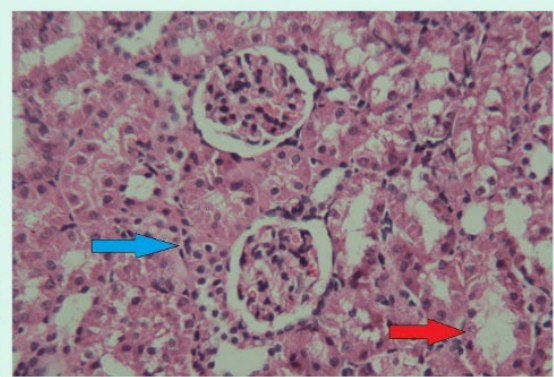

(d) $\mathrm{ZGO}+\mathrm{Cd}$

Fig. 3. Photomicrographs of rats' kidneys. (A) control, (B) ZGO, (C) $\mathrm{CdCl}_{2}$, and (D) $\mathrm{ZGO}-\mathrm{CdCl}_{2}$ groups. Cd intoxication caused congested glomeruli (black arrow), severe infiltration of inflammatory cells (blue arrow), cytoplasmic vacuolation, and tubular atrophy or desquamation and degeneration (red arrow). However, ZGO co-treatment limited the pathological alterations caused by $\mathrm{CdCl}_{2}$ intoxication. Sections were stained with Hematoxylin and eosin (H\&E), 400x magnification.

We noticed an increasing trend $(p<0.05)$ in kidney function parameters (urea and creatinine levels) in all $\mathrm{CdCl}_{2}$-intoxicated groups compared to the corresponding values in the healthy animals. However, the Cd-intoxicated rats treated with ZGO showed markedly diminished $(p<0.05)$ urea and creatinine levels compared to the corresponding values in the $\mathrm{CdCl}_{2}$-exposed rats (Figure 4).
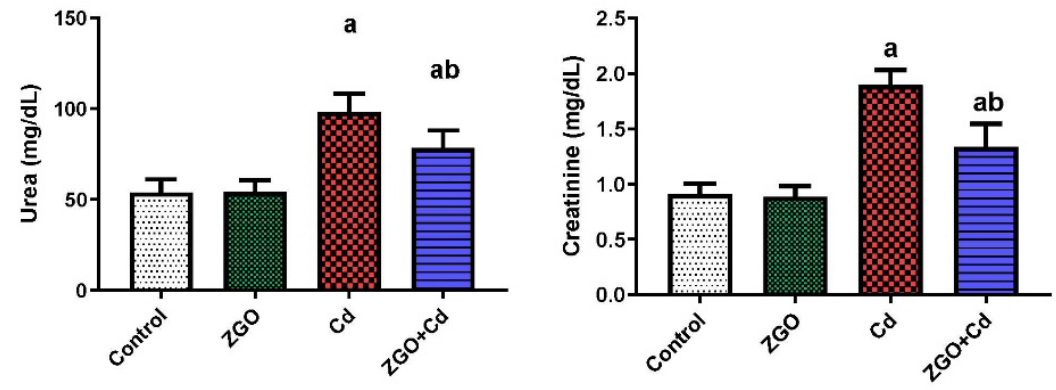

Fig. 4. Effects of zingerone (ZGO) on the serum level of kidney function parameters (urea and creatinine) in $\mathrm{CdCl}_{2}$-intoxicated rats. Data are expressed as the mean $\pm \mathrm{SD}(\mathrm{n}=7)$. ${ }^{\mathrm{a}} p<0.05 \mathrm{vs}$. the control rats; ${ }^{b} p<0.05$ vs. the Cd-intoxicated rats. 
Acute exposure to the $\mathrm{CdCl}_{2}$ administered resulted in the altered profile of oxidative stress marker. In all groups intoxicated with $\mathrm{CdCl}_{2}$ exhibited a considerable elevation $(p<0.05)$ in TBARS and NO levels in the renal tissues, whereas, the GSH content was significantly decreased $(p<0.05)$ compared to the corresponding values in the healthy rats. However, $\mathrm{CdCl}_{2}$-intoxicated rats treated with ZGO exhibited extensively diminished $(p<0.05)$ TBARS and $\mathrm{NO}$ levels and a significant increase in $\mathrm{GSH}$ content compared to the $\mathrm{CdCl}_{2}$-exposed rats that were not treated with ZGO (Figure 5).
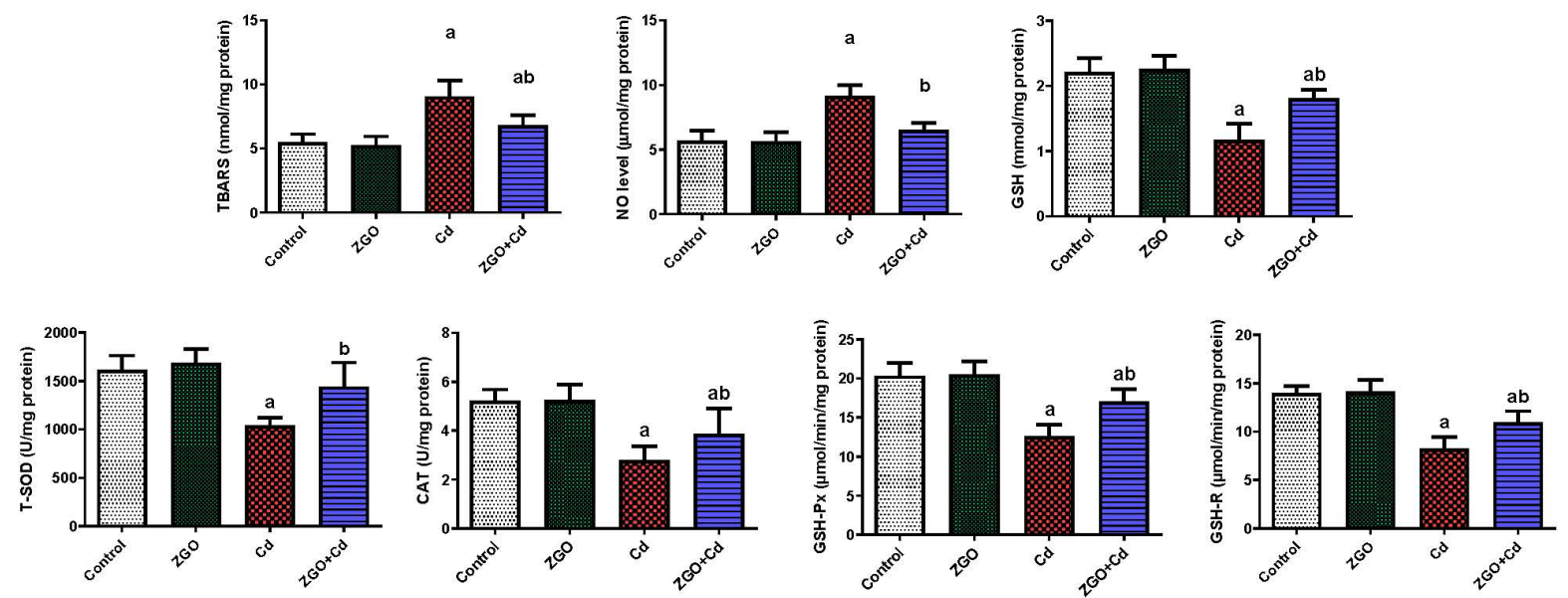

Fig. 5. Effects of zingerone (ZGO) on the oxidative stress markers (TBARS, NO, GSH, T-SOD, CAT, GSH-Px, $\mathrm{GSH}-\mathrm{R})$ in $\mathrm{CdCl}_{2}$-intoxicated rats. Data are expressed as the mean $\pm \mathrm{SD}(\mathrm{n}=7) .{ }^{\mathrm{a}} p<0.05$ vs. the control rats; ${ }^{\mathrm{b}} p<0.05$ vs. the Cd-intoxicated rats.

Furthermore, $\mathrm{CdCl}_{2}$ intoxication significantly suppressed $(p<0.05)$ the activities of enzymatic antioxidants (T-SOD, GSH-Px, CAT, and GSH-R) compared to the consequent values in the healthy rats (Figure 5 ). In contrast, treatment of the rats with ZGO significantly promoted $(p<0.05)$ the activities of the antioxidant enzyme compared to that in the $\mathrm{CdCl}_{2}$-intoxicated rats. Interestingly, the rats that were treated alone with ZGO showed a marked enhancement $(p<0.05)$ in the activity of CAT compared to the $\mathrm{CdCl}_{2}$ rats.

There was a considerable elevation $(p<0.05)$ in the inflammatory markers (TNF-a and IL-1 $\beta$ levels) in Cd-exposed rats compared to that in the control values (Figure 6). In contrast to the $\mathrm{CdCl}_{2}$-intoxicated rats, ZGO treatment prompted a significant diminish $(p<0.05)$ in the levels of these inflammatory markers in the renal tissue.
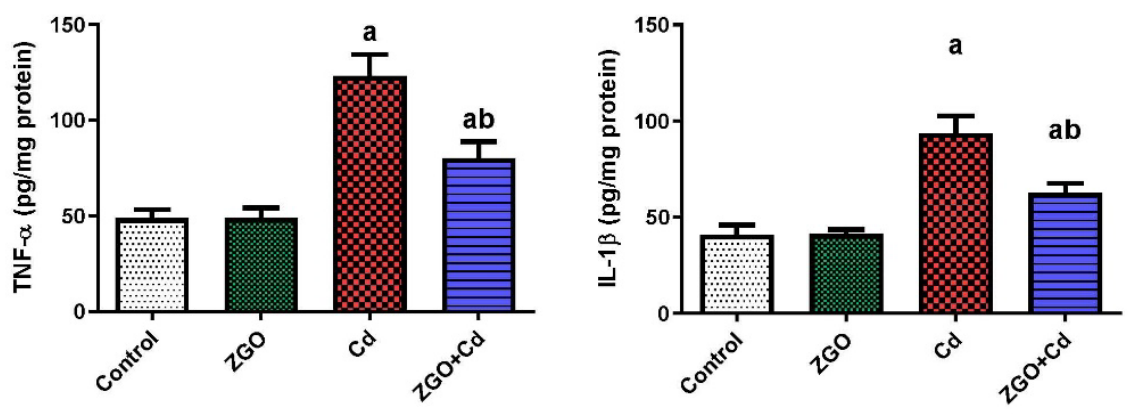

Fig. 6. Effects of zingerone (ZGO) on the pro-inflammatory cytokines (TNF-a and IL-1 $\beta$ ) in $\mathrm{CdCl}_{2}$ intoxicated rats. Data are expressed as the mean $\pm \mathrm{SD}(\mathrm{n}=7)$. ${ }^{\mathrm{a}} p<0.05 \mathrm{vs}$. the control rats; ${ }^{\mathrm{b}} p<0.05 \mathrm{vs}$. the $\mathrm{Cd}$-intoxicated rats. 
The obtained results indicated that the levels of Bax and caspase-3 were extensively elevated $(p<0.05)$ in the kidney of the $\mathrm{CdCl}_{2}$-exposed rats while that of $\mathrm{Bcl}-2$ were decreased. However, ZGO treatment restrained Cd-induced cell death in the kidney (Figure 7).
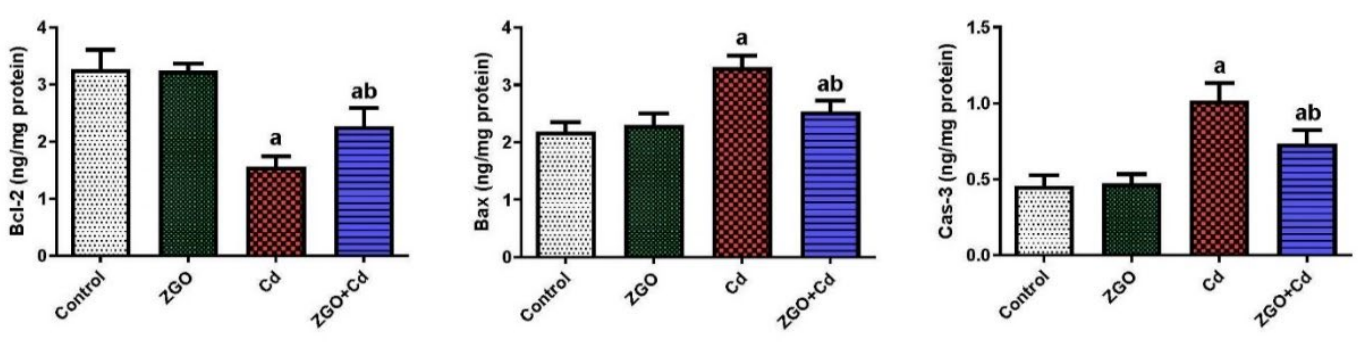

Fig. 7. Effects of zingerone (ZGO) on the apoptotic markers ( $\mathrm{Bcl}-2, \mathrm{Bax}$, and caspase- 3 ) in $\mathrm{CdCl}_{2}$-intoxicated rats. Data are expressed as the mean $\pm S D(n=7)$. ${ }^{a} p<0.05$ vs. the control rats; ${ }^{b} p<0.05$ vs. the

Cd-intoxicated rats.

\section{DISCUSSION}

Cadmium is an extremely toxic heavy metal with a growing associated risk of malignancy. It is distributed through the circulatory system and dispersed broadly in the body, with a principal accumulation in the kidney and hence induced nephrotoxicity ${ }^{13}$. Previous studies support the influence of oxidative stress, inflammation, and apoptosis participates in the etiology and pathophysiology of Cd-induced nephrotoxicity ${ }^{14}$. In the present work, the modulatory role of ZGO, to restrain Cd-induced nephrotoxicity, was investigated and discussed that (i) ZGO administration significantly improved Cd-induced kidney injury, as evidenced by decreasing urea and creatinine; (ii) ZGO treatment significantly suppressed Cd caused oxidative stress confirmed by decreasing TBARS and NO and increasing GSH and antioxidant defense system; and (iv) ZGO administration prevented the inflammation and apoptosis in Cd-intoxicated rats by inhibiting the inflammatory markers as TNF- $\mathrm{a}, \mathrm{IL}-1 \beta, \mathrm{Bax}$, and caspase-3 and enhancing Bcl-2.

Histopathological examination revealed $\mathrm{Cd}$-induced kidney lesions. Photomicrographs of the kidney showed that cadmium exerted many pathological lesions characterized by visible dilation in the sinusoidal space, severe congestion in the glomerulus, and noticeable infiltrates of inflammatory cells. Also, the renal tubules lost their histological details. Those pathological alterations were associated with high serum urea and creatinine levels. According to Wang et al. ${ }^{15}$ and Ali et al. ${ }^{16}$, an increase in urea and creatinine levels is a sign of renal tubular injury due to nephrotoxicity induced by $\mathrm{Cd}$. This is due to the failure of the kidneys to excrete these markers. However, the intensity of these elevations of the markers and $\mathrm{Cd}$ accumulation were encountered in the presence of ZGO administration. Researchers have shown that ZGO has a powerful nephroprotective effect against toxicants that cause kidney injury ${ }^{17,18}$. Furthermore, the reduction in Cd level in kidney tissue following ZGO treatment may be due to the capability of ZGO to improve the synthesis of metallothionein and enhance the execration of $\mathrm{Cd}$ from the kidney ${ }^{19}$. The obtained results in accordance with Kandemir et al. ${ }^{8}$ who demonstrated that ZGO administration was effectively prevented cisplatin-induced nephrotoxicity by restraining the rise in serum urea and creatinine levels.

One of the probable mechanisms of Cd-induced nephrotoxicity is the stimulation of oxidative stress. Free radical overproduction and lipid peroxidation induced by Cd intoxication and depletion of antioxidant molecules were implicated in renal toxicity in the present study. There are many pieces of evidence of the production of free radicals in living organisms following $\mathrm{Cd}$ exposure. $\mathrm{Cd}$-stimulated $\mathrm{O}_{2}{ }^{\circ}-\mathrm{H}_{2} \mathrm{O}_{2}$, and $\mathrm{OH}^{\circ}$ - which are often coincided with activation of redox-sensitive internal transcription factors like nuclear factor kappa B (NF-kB), a fundamental transcription factor that plays a critical role in stress responses, apoptosis, and inflammation ${ }^{15}$. Furthermore, $\mathrm{Cd}$ interacts with protein-and non-protein mixed disulfides causing GSH pool reduction. Additionally, the obtained results revealed that the inhibition of 
the antioxidant defense system is due to the suppression of their gene transcription in the renal tissue. The inhibition of CAT and GSH-Px after $\mathrm{Cd}$ intoxication has been attributed to Fe and Se depletion that very important for CAT and GSH-Px functions, respectively ${ }^{20}$. Moreover, the inhibition of T-SOD could be due to the interaction between $\mathrm{Cd}$ and the protein part of SOD which causes alternation in the enzyme configuration, thus inhibiting its catalytic property ${ }^{21}$. It has been assumed that the antioxidants may alleviate Cd-induced oxidative stress due to their capacity to quench free radicals and enhance the activity of endogenous antioxidant defense enzymes ${ }^{22}$. Interestingly, ZGO in the present experiment showed a strong antioxidant effect against $\mathrm{Cd}$-induced nephrotoxicity. The obtained results are in agreement with Alibakhshi et al. ${ }^{17}$ who found that ZGO promoted the activities of antioxidant enzyme and diminished TBARS formation in rats intoxicated with cisplatin. In addition, ZGO was found to prevent oxidative stress in kidney tissue of rats exposed to carbon tetrachloride ${ }^{11}$.

Cellular damage and oxidative stress are suggested as key inflammation initiators in kidney disease. The innate immune restraint functions as a substantial line of protection against pathogenic factors. Both TNF- $\alpha$ and IL-1 are cytokines desired for stimulating the innate immune reaction, mediating the mobilization, activation, and adhesion of circulating WBCs ${ }^{23}$. Our data indicated that $\mathrm{Cd}$-intoxication stimulated inflammation in kidney tissue as evidenced by increased levels of TNF-a, IL-1B. The obtained results were constant with the results found by Wang et al. ${ }^{15}$ who found that the concentrations of TNF- $\alpha, I L-1 \beta$ in the renal tissue were increased following $\mathrm{Cd}$ intoxication. Furthermore, $\mathrm{Cd}$ exposure provoked inflammatory cells to infiltrate into the kidney tissue that explains the increment in NO level via enhancing the expression of inducible nitric oxide synthase, a rate-limiting enzyme in NO biosynthesis. In contrast, treatment with ZGO caused a considerable reverse of Cd-induced inflammatory response in the kidney tissues. The protective effect of ginger oil and extract against $\mathrm{Cd}$ induced nephrotoxicity was already documented by other researchers ${ }^{24,25}$. However, the protective effect of ZGO against Cd was not investigated previously yet. In concordance with the study of Kucukler et al. ${ }^{26}, \mathrm{ZGO}$ administration restrained renal inflammation in rats caused by vancomycin. Ahmad et al. ${ }^{27}$ also reported that ZGO prevented inflammatory responses by attenuating NF-KB translocation and down-regulating IL-1 $\beta$ and TNF- $\alpha$ in diabetic rats.

Apoptosis, a well-regulated form of cellular death, has been documented as an essential mediator of kidney injury and inflammation in renal diseases. Apoptosis is activated through the extrinsic and intrinsic pathways ${ }^{26}$. In the current experiment, we found that $\mathrm{CdCl}_{2}$ exposure caused cell death by enhancing caspases-3 and Bax levels and diminishing Bcl-2 levels. Bcl-2/Bax imbalance leading to cytochrome $c$ leakage into the cytoplasm from the mitochondria that in turn stimulates the activation of caspase- 3 that is also responsible for apoptosis ${ }^{28}$. Moreover, the $\mathrm{Cd}$-initiated apoptosis cascade has been confirmed to be associated with oxidative pressure in renal cells ${ }^{29}$. Interestingly, treatment with ZGO suppressed apoptosis in the kidney tissue. Kucukler et al. ${ }^{26}$ demonstrated that ZGO protected the kidney tissue by preventing p53, caspase-8, cytochrome $c$, Bax, and caspase-3 over-expression and enhancing Bcl-2 protein expression. Furthermore, Safhi ${ }^{11}$ found that ZGO reduced caspase-3 activity in the kidney tissue of the rats intoxicated with carbon tetrachloride.

\section{CONCLUSION}

Our study indicated that ZGO is useful in preventing the nephrotoxicity induced by $\mathrm{CdCl}_{2}$. In addition, ZGO achieves these effects via various mechanisms that result in the mitigation of $\mathrm{CdCl}_{2}$-induced renal toxicity including suppression of oxidative pressure, inflammatory response, and apoptosis in $\mathrm{CdCl}_{2}$-intoxicated rats. The obtained data may provide useful information for further pharmacological and clinical practice use of ZGO against cadmium toxicity.

\section{ACKNOWLEDGEMENTS}

Not applicable. 


\section{REFERENCES}

1. Albeltagy RS, Mumtaz F, Moneim AEA, El-Habit OH. N-acetylcysteine reduces miR-146a and NFkappaB p65 inflammatory signaling following cadmium hepatotoxicity in rats. Biol Trace Elem Res. 2021;199(12):4657-65. http://dx.doi.org/10.1007/s12011-021-02591-8. PMid:33454892.

2. Elmallah MIY, Elkhadragy MF, Al-Olayan EM, Moneim AEA. Protective effect of fragaria ananassa crude extract on cadmium-induced lipid peroxidation, antioxidant enzymes suppression, and apoptosis in rat testes. Int J Mol Sci. 2017;18(5):957. http://dx.doi.org/10.3390/ijms18050957. PMid:28475120.

3. Al-Brakati A et al. Possible role of kaempferol in reversing oxidative damage, inflammation, and apoptosis-mediated cortical injury following cadmium exposure. Neurotox Res. 2021;39(2):198-209. http://dx.doi.org/10.1007/s12640-020-00300-2. PMid:33141427.

4. Hu J, Zhang B, Du L, Lu Q. Resveratrol ameliorates cadmium induced renal oxidative damage and inflammation. Int J Clin Exp Med. 2017;10:7563-72.

5. Prozialeck WC, Edwards JR. Mechanisms of cadmium-induced proximal tubule injury: new insights with implications for biomonitoring and therapeutic interventions. J Pharmacol Exp Ther. 2012;343(1):2-12. http://dx.doi.org/10.1124/jpet.110.166769. PMid:22669569.

6. Zhai Q, Wang G, Zhao J, Liu X, Tian F, Zhang H, Chen W. Protective effects of Lactobacillus plantarum CCFM8610 against acute cadmium toxicity in mice. Appl Environ Microbiol. 2013;79(5):1508-15. http://dx.doi.org/10.1128/AEM.03417-12. PMid:23263961.

7. Kaygusuzoglu E, Caglayan C, Kandemir FM, Yıldırım S, Kucukler S, Kılınc MA, Saglam YS. Zingerone ameliorates cisplatin-induced ovarian and uterine toxicity via suppression of sex hormone imbalances, oxidative stress, inflammation and apoptosis in female wistar rats. Biomed Pharmacother. 2018;102:517-30. http://dx.doi.org/10.1016/j.biopha.2018.03.119. PMid:29587238.

8. Kandemir FM, Yildirim S, Caglayan C, Kucukler S, Eser G. Protective effects of zingerone on cisplatininduced nephrotoxicity in female rats. Environ Sci Pollut Res Int. 2019;26(22):22562-74. http://dx.doi.org/10.1007/s11356-019-05505-3. PMid:31165450.

9. Elshopakey GE, Almeer R, Alfaraj S, Albasher G, Abdelgawad ME, Abdel Moneim AE, Essawy EA. Zingerone mitigates inflammation, apoptosis and oxidative injuries associated with renal impairment in adriamycinintoxicated mice. Toxin Rev. 2021. In press. http://dx.doi.org/10.1080/15569543.2021.1923528.

10. Cheong KO, Shin D, Bak J, Lee C, Kim KW, Je NK, Chung HY, Yoon S, Moon J. Hepatoprotective effects of zingerone on carbon tetrachloride-and dimethylnitrosamine-induced liver injuries in rats. Arch Pharm Res. 2016;39(2):279-91. http://dx.doi.org/10.1007/s12272-015-0696-2. PMid:26667466.

11. Safhi MM. Nephroprotective effect of Zingerone against CCl4-induced renal toxicity in Swiss albino mice: molecular mechanism. Oxid Med Cell Longev. 2018;2018:2474831. http://dx.doi.org/10.1155/2018/2474831. PMid:29636837.

12. Elkhadragy MF, Al-Olayan EM, Al-Amiery AA, Moneim AEA. Protective effects of fragaria ananassa extract against cadmium chloride-induced acute renal toxicity in rats. Biol Trace Elem Res. 2018;181(2):378-87. http://dx.doi.org/10.1007/s12011-017-1062-7. PMid:28567583.

13. Kowalczyk E, Kopff A, Fijalkowski P, Kopff M, Niedworok J, Blaszczyk J, Kedziora J, Tyslerowicz P. Effect of anthocyanins on selected biochemical parameters in rats exposed to cadmium. Acta Biochim Pol. 2003;50(2):543-8. http://dx.doi.org/10.18388/abp.2003_3707. PMid:12833179.

14. Sanjeev S, Bidanchi RM, Murthy MK, Gurusubramanian G, Roy VK. Influence of ferulic acid consumption in ameliorating the cadmium-induced liver and renal oxidative damage in rats. Environ Sci Pollut Res Int. 2019;26(20):20631-53. http://dx.doi.org/10.1007/s11356-019-05420-7. PMid:31104231.

15. Wang X, Wang T, Pan T, Huang M, Ren W, Xu G, Amin HK, Kassab RB, Moneim AEA. Senna alexandrina extract supplementation reverses hepatic oxidative, inflammatory, and apoptotic effects of cadmium chloride administration in rats. Environ Sci Pollut Res Int. 2020;27(6):5981-92. http://dx.doi.org/10.1007/s11356-019-07117-3. PMid:31863371.

16. Ali S, Hussain S, Khan R, Mumtaz S, Ashraf N, Andleeb S, Shakir HA, Tahir HM, Khan MKA, Ulhaq M. Renal toxicity of heavy metals (cadmium and mercury) and their amelioration with ascorbic acid in rabbits. Environ Sci Pollut Res Int. 2019;26(4):3909-20. http://dx.doi.org/10.1007/s11356-018-38198. PMid:30547340.

17. Alibakhshi T, Khodayar MJ, Khorsandi L, Rashno M, Zeidooni L. Protective effects of zingerone on oxidative stress and inflammation in cisplatin-induced rat nephrotoxicity. Biomed Pharmacother. 2018;105:225-32. http://dx.doi.org/10.1016/j.biopha.2018.05.085. PMid:29857302. 
18. Türk E, Güvenç M, Cellat M, Uyar A, Kuzu M, Ağgül AG, Kırbaş A. Zingerone protects liver and kidney tissues by preventing oxidative stress, inflammation, and apoptosis in methotrexate-treated rats. Drug Chem Toxicol. 2020. In press. http://dx.doi.org/10.1080/01480545.2020.1804397. PMid:32781857.

19. Mao QQ, Xu XY, Cao SY, Gan RY, Corke H, Beta T, Li HB. Bioactive compounds and bioactivities of ginger (Zingiber officinale Roscoe). Foods. 2019;8(6):185. http://dx.doi.org/10.3390/foods8060185. PMid:31151279.

20. Almeer RS, Alarifi S, Alkahtani S, Ibrahim SR, Ali D, Moneim A. The potential hepatoprotective effect of royal jelly against cadmium chloride-induced hepatotoxicity in mice is mediated by suppression of oxidative stress and upregulation of Nrf2 expression. Biomed Pharmacother. 2018;106:1490-8. http://dx.doi.org/10.1016/j.biopha.2018.07.089. PMid:30119224.

21. Mumtaz F, Albeltagy RS, Diab MSM, Moneim AEA, El-Habit OH. Exposure to arsenite and cadmium induces organotoxicity and miRNAs deregulation in male rats. Environ Sci Pollut Res Int. 2020;27(14):17184-93. http://dx.doi.org/10.1007/s11356-020-08306-1. PMid:32152865.

22. Elkhadragy MF, Kassab RB, Metwally DM, Almeer R, Abdel-Gaber R, Al-Olayan EM, Essawy EA, Amin $\mathrm{HK}$, Moneim AEA. Protective effects of Fragaria ananassa methanolic extract in a rat model of cadmium chloride-induced neurotoxicity. Biosci Rep. 2018;38(6):BSR20180861. http://dx.doi.org/10.1042/BSR20180861. PMid:30291211.

23. Ott LW et al. Tumor Necrosis Factor-alpha- and interleukin-1-induced cellular responses: coupling proteomic and genomic information. J Proteome Res. 2007;6(6):2176-85. http://dx.doi.org/10.1021/pr060665l. PMid:17503796.

24. Akinyemi AJ, Adeniyi PA. Effect of essential oils from ginger (Zingiber officinale) and turmeric (Curcuma longa) rhizomes on some inflammatory biomarkers in cadmium induced neurotoxicity in rats. J Toxicol. 2018;2018:4109491. http://dx.doi.org/10.1155/2018/4109491. PMid:30402094.

25. Gabr SA, Alghadir AH, Ghoniem GA. Biological activities of ginger against cadmium-induced renal toxicity. Saudi J Biol Sci. 2019;26(2):382-9. http://dx.doi.org/10.1016/j.sjbs.2017.08.008. PMid:31485182.

26. Kucukler S, Darendelioğlu E, Caglayan C, Ayna A, Yıldırım S, Kandemir FM. Zingerone attenuates vancomycin-induced hepatotoxicity in rats through regulation of oxidative stress, inflammation and apoptosis. Life Sci. 2020;259:118382. http://dx.doi.org/10.1016/j.Ifs.2020.118382. PMid:32898532.

27. Ahmad B, Rehman MU, Amin I, Mir MUR, Ahmad SB, Farooq A, Muzamil S, Hussain I, Masoodi M, Fatima B. Zingerone (4-(4-hydroxy-3-methylphenyl) butan-2-one) protects against alloxan-induced diabetes via alleviation of oxidative stress and inflammation: probable role of NF-kB activation. Saudi Pharm J. 2018;26(8):1137-45. http://dx.doi.org/10.1016/j.jsps.2018.07.001. PMid:30532634.

28. Ly JD, Grubb DR, Lawen A. The mitochondrial membrane potential (deltapsi(m)) in apoptosis; an update. Apoptosis. 2003;8(2):115-28. http://dx.doi.org/10.1023/A:1022945107762. PMid:12766472.

29. Yin M, Jiang N, Guo L, Ni Z, Al-Brakati AY, Othman MS, Abdel Moneim AE, Kassab RB. Oleuropein suppresses oxidative, inflammatory, and apoptotic responses following glycerol-induced acute kidney injury in rats. Life Sci. 2019;232:116634. http://dx.doi.org/10.1016/j.lfs.2019.116634. PMid:31279782.

\section{Authors' contributions}

SMD and RP equally contributed in conception and design; SMD carried on data collection and analysis, drafting the manuscript, etc; FM analyzed the data. All authors read and approved the final manuscript. 